DOI: $10.4274 /$ tpa.45.257

\title{
Yenidoğan yoğun bakım birimindeki hastalarda temassız infrared alın termometresi ile standart termometrelerin karşılaştırıması
}

\section{Comparison of non-contact infrared forehead thermometer to standard temperature measurement in neonatal intensive care unit patients}

\author{
Emrah Can, Ali Bülbül, Sinan Uslu, Asiye Nuhoğlu \\ Şişli Etfal Eğitim ve Araştırma Hastanesi Yenidoğan Kliniği, İstanbul, Türkiye
}

\section{Özet}

Amaç: Bu çalışmada yenidoğan döneminde temassız infrared alın termometresi ile civalı termometre ve dijital termometre ölçümlerinin karşılaştırılması amaçlandı.

Gereç ve Yöntem: Çalışmaya rastgele seçilmiş 179 yenidoğan alındı. Isı ölçümleri infrared derece ile alından, diğer iki termometre ile de koltuk altından olmak üzere eş zamanlı olarak üç farklı teknik ile yapıldı. Ölçümlerde Thermoflash LX-26 (France-China) marka temassız infrared alın termometresi, MC-203-E (Omron Health Care, Europe) dijital termometre ve civalı cam geleneksel termometre kullanıldı. Her ölçüm cihazı ile 2091 defa ölçüm olmak üzere toplam 6273 ölçüm yapıldı.

Bulgular: Elde edilen ortalama değerler ve standart sapmalar sırasıyla temassız infrared alın termometresi için $37,2 \pm 0,5{ }^{\circ} \mathrm{C}$, civalı termometre için $36,7 \pm 0,4{ }^{\circ} \mathrm{C}$, ve dijital termometre için $36,6 \pm 0,4{ }^{\circ} \mathrm{C}$ olarak saptandı. Bland Altman eğrisine göre temassız infrared alın termometresi ile yapılan ölçümlerin $\% 95$ güven aralığında, kabul edilen sınırlarda civalı termometre sonuçlarına göre $-0.37^{\circ} \mathrm{C}$ ve $+1.54^{\circ} \mathrm{C}$ aralığı arasında, dijital termometre sonuçlarına göre $-0,40^{\circ} \mathrm{C}$ ve $+1,54^{\circ} \mathrm{C}$ aralığında olduğu saptandı. Temassız infrared alın termometresinin duyarlılı̆ı yüksek (\%81), özgünlüğü düşük (\%50) olarak belirlendi [\%95 güven aralığı $(41,6-58,4)]$.

Çıkarımlar: Temassız infrared alın termometresinin yenidoğan yoğun bakım birimlerinde yatan bebeklerde vücut ısısının değerlendirilmesi amacıyla kullanılamayacağı sonucuna varıldı. (Türk Ped Arş 2010; 45: 257-63)

Anahtar sözcükler: Civalı termometre, dijital termometre, temassız infrared alın termometresi, vücut ısısı, yenidoğan

\section{Summary}

Aim: In this study, we aimed to compare non-contact infrared forehead thermometer measurement with the mercury thermometer and digital thermometer measurements in the neonatal period.

Material and Method: A total of 179 newborns who were admitted to our hospital were enrolled, and simultaneous temperature measurements were performed via three devices. Mesaurements were made from forehead with non-contact infrared thermometer and from axillar region with digital thermometers and conventional thermometers. Thermoflash LX-26 (France-China) thermometer was used for non-contact infrared mesasurement, MC-203-E (Omron Health Care, Europe) thermometer for digital measurement and glass mercury thermometer for conventional axillary measurement. A total of 6273 measurements were performed, being 2091 measurement for each method.

Results: The mean results of the non-contact infrared forehead thermometer, mercury thermometers and digital thermometer were found as $37.2 \pm 0.5{ }^{\circ} \mathrm{C}, 36.7 \pm 0.4{ }^{\circ} \mathrm{C}$, and $36.6 \pm 0.4{ }^{\circ} \mathrm{C}$ respectively. The Bland-Altman plots differences suggest that $95 \%$ of the non-contact infrared forhead thermometer readings were within the limits of agreement, which is -0.37 and $+1.54{ }^{\circ} \mathrm{C}$ range of mercury thermometer and -0.40 and $+1.54{ }^{\circ} \mathrm{C}$ range of digital thermometer respectively. The sensitivity and specificity of the non-contact infrared thermometer were found as $81 \%$ and $50 \%$ respectively [95\% $\mathrm{Cl}(41.6-58.4)]$.

Conclusions: We conclude that the non-contact infrared thermometer can not be recommended for assessment of body temperature in newborns admitted to neonatal intensive care unit. (Turk Arch Ped 2010; 45: 257-63)

Key words: Body temperature, digital thermometer, mercury thermometer, newborn, non-contact infrared forehead thermometer

Yazışma Adresi/Address for Correspondence: Dr. Emrah Can, Şişli Etfal Eğitim ve Araştırma Hastanesi-Yenidoğan Kliniği, Şişli, İstanbul, Türkiye E-posta: canemrahcan@yahoo.com Geliş Tarihi/Received: 21.12.2009 Kabul Tarihi/Accepted: 12.04.2010

Türk Pediatri Arşivi Dergisi, Galenos Yayınevi tarafindan basilmıştr. / Turkish Archives of Pediatrics, published by Galenos Publishing 


\section{Giriş}

Yenidoğan bebeklerde vücut ısısı yaşamsal değişkenlerin en önemlilerinden birisidir. Vücut ısısının ölçümü çocukluk yaş grubunda genellikle ateşin tespit edilmesi amacıyla yapılırken, yenidoğan bebeklerde, bebeğin vücut ısısını koruyup koruyamadığının belirlenmesi amacıyla yapılmaktadır (1). Vücut ısısının günlük ritminin olduğu ve bu ritmin hastalık varlığı, ortam sıcaklığı ya da giysi gibi birçok etkenden etkilenebildiği bilinmektedir. Amerikan Çocuk Akademisi'ne (AAP) göre vücut ısısının 97-100,4 ${ }^{\circ}$ Fahrenheit $\left(36,1-38^{\circ} \mathrm{C}\right)$ arasında olması normal olarak kabul edilmektedir (1). Çocuklarda vücut ısı ölçümünün en doğru ve en uygun yöntemi yıllardır araştırılan bir konudur. Civalı termometre kullanımı civa ile ilişkili sağlık sorunları nedeniyle giderek terk edilmektedir. Civanın toksik etkisi, solunum yoluyla zehirli buharın alınması ya da doğrudan deri yoluyla emilmesi sonucunda olmaktadır (2). İleri derecede erken doğmuş yenidoğan bebeklerin yüksek deri geçirgenliğinin olması yanında özellikle bu bebeklerin bakımlarının sıcak ortamlarda yapılıyor olması civanın daha kolay buharlaşmasına ve dolayısıyla buhar yolu ile civanın emiliminin artmasına sebep olabilmektedir (3). Vücut ısısının ölçümünde klasik olarak kullanılan ağız, rektal ve koltuk altı bölgelerinden civalı termometre ile ölçüm yöntemlerine ek, infrared timpanik membran termometresi, temporal arter termometresi ve temassız infrared alın termometresi gibi yeni ölçüm yöntemlerinin kullanıma girmesi; varolan en uygun ölçüm yönteminin hangisi olması geektiğine ait karmaşanın daha da artmasına neden olmuştur (1). Günümüzde, vücut ısı ölçümü için yapılan çalışmalarda çeşitli girişimsel olmayan ısı ölçüm yaklaşımlarının girişimsel yöntemlere göre konfor, etkinlik ve enfeksiyon kontrolü üstünlükleri sağladığı gösterilmiştir (3). İnfrared termometre ile ölçüm teknolojisi, infrared timpanik membran ve temporal arter termometresinin geliştirilmesi için kullanılmıştır (4). İnfrared timpanik membran termometresi evde sağlıklı çocuklarda ve yenidoğan bebeklerde kullanımı yararlı ve pratik görünmekle birlikte, doğruluğu ve güvenilirliği ile ilgili yapılan çalışmalarda çelişkili sonuçlar bildirilmiştir $(5,6)$. Ancak infrared temassız alın termometresi ile yapılan çalışmalar, sağlıklı çocuklarda ve süt çocuklarında kullanımının pratik ve etkinliğinin olduğunu bildirmektedir (7). Enfeksiyon gelişiminde yüksek riske sahip çocuklarda (nötropenik, immün yetersizliği olan veya organ nakli olanlar) bu yöntemin, hızlı ve temassız vücut ısısı ölçümünü sağlayabilmesi nedeniyle faydalı olduğu bilinmektedir (7). Temasın olmaması, kullanımının kolaylığı ve ölçüm süresinin kısalığı nedenleriyle bazı merkezler tarafından enfeksiyon kontrol önlemi için ölçüt olarak kabul edilmiştir (4). Ancak yenidoğan döneminde vücut ısısının infrared alın termometresiyle ölçümü ve etkinliği üzerine bir çalışma bulunmamaktadır. Bu nedenle, çalışmamızda yenidoğan bebeklerde ısı ölçümünün değerlendirilmesi için birimimizde düzenli olarak kullanılan diji- tal termometre ile geleneksel civalı termometre ölçümlerinin temassız infrared alın termometresi ölçümleri ile karşılaştırılması amaçlandı.

\section{Gereç ve Yöntem}

Çalışma Hastanemiz Yenidoğan Yoğun Bakım Birimi'nde (YYBB) Ağustos 2008-Aralık 2009 tarihleri arasında, ileriye dönük olarak, YYBB'ye yatırılan 179 erken ve zamanında doğmuş bebekte yapıldı. Kronolojik yaşı 28 gün üzerinde olan, periferik dolaşım bozukluğu olan, ağır konjenital kalp hastalığı, ağır doğuştan malformasyonu, gelişimsel beyin anomalisi olan ve cerrahi girişim uygulanan yenidoğan bebekler çalışma dışında bırakıldı. Tüm termometrelerin kullanımı ve standardizasyonu çalışma öncesinde, üretici firma teknik elemanları tarafından kontrol edildi. Çalışma öncesinde ailelere ölçümler ve termometreler hakkında detaylı bilgi verilerek bilgilendirilmiş onam formu alındı. Çalışmada Thermoflash LX-26 (Fransa-Çin) temassız infrared alın termometresi, MC-203-E (Omron Sağlık, Avrupa) dijital derece ve geleneksel civalı cam termometre kullanıldı. Çalışma öncesinde hastanemiz etik kurulu onayı alındı. Yapılan üç ısı ölçümü her yenidoğan için aynı kişi tarafından koltuk altı ve alın bölgelerinden yapıldı. Tüm ölçümler, vücut ısısının gündüz değişkenliğinin etkisini dışlamak amacıyla sabah 10 ile 11 saatleri arasında yapıldı. Çevre ısısının çalışmaya etkisini en aza indirmek amacıyla yoğun bakımdaki ortam ısısı yaklaşık $25^{\circ} \mathrm{C}$ 'de ve nem \%40-60 arasında merkezi klima sistemi ile sabit tutuldu. Ölçüm yapıldığında bebeğin izlem yeri (küvöz, açık yatak ve kot) kaydedildi. Açık ısıtmalı yataklarda ısıtma seviyesi tüm bebekler için idame düzeyinde tutuldu. Küvöz sıcaklıkları ise mevcut standart tablolardan gebelik yaşına göre uygun olan sıcaklık ölçüt alınarak ayarlandı (8). Vücut ısısı ölçümleri ilk olarak koltuk altı dijital termometreyle ardından civalı cam termometre ve infrared alın termometresiyle kaydedildi. Tüm ölçümler aynı koltuk altından Celcius $\left({ }^{\circ} \mathrm{C}\right)$ ile ve aynı süreyle yapıldı. Ölçümler civalı termometre ile üç dakikada, dijital termometre ile yaklaşık 60 saniyede, infrared temassız alın termometresi ile alından yaklaşık 10-15 cm uzaklıktan olacak şekilde 30 saniyede tamamlandı.

\section{İstatistiksel analiz}

Üç farklı yöntemde elde edilen ölçümler kendi aralarında karşılaştırıldı. Ölçümün yapıldığı yerin (küvöz, açık yatak ve beşik), bebeğin gebelik haftasının ve ağırlığının ölçüm etkinliği üzerine etkisi incelendi. İstatistiksel analizlerde SPSS 16,0 ve Medcalc programları kullanıldı. Değişkenler arası hesaplamalarda Paired Samples t testi ve tekrarlayan ölçümlerde ANOVA testi kullanıldı. Ölçüm yöntemlerinin kendi aralarındaki ilişkinin değerlendirilmesinde Bland Altman eğrileri kullanıldı. Daha önce konu ile 
ilgili benzer yapılan çalışmalarda anlamlı farklılık olarak $\mathrm{p}$ değerinin $<0,001$ kabul edildiği ve sonuçlarımızın diğer çalışmalar ile karşılaştırılabilmesi için, $p$ değerinin $<0,001$ olması istatistiksel olarak anlamlı kabul edildi.

\section{Bulgular}

Çalışmaya yaşları 0-28 gün arasında değişen, toplam 179 yenidoğan bebek alındı. 179 bebekten 2091'er adet olmak üzere toplam 6243 adet ölçüm yapıldı. Hastaların klinik özellikleri Tablo 1'de sunuldu. Ölçüm esnasında bebeklere konulan tanılar Tablo 2'de sunuldu. Ölçümlerin 1390'। $(\% 66,5)$ küvözde, 371'i $(\% 17,7)$ kotta, $330(\% 15,8)$ tanesi açık yatakta alındı. Civalı termometre ölçümlerinde ortalama $36,7 \pm 0,34{ }^{\circ} \mathrm{C}(35,2-38,9)$, dijital termometrede ortalama $36,6 \pm 0,4^{\circ} \mathrm{C}(35,2-38,2)$, temassız infrared alın termometresinde ortalama $37,2 \pm 0,4^{\circ} \mathrm{C}(35,8-37,2)$ değerleri saptandı (Tablo 3).

Her üç ölçüm yönteminden elde edilen ortalama değerlerin karşılaştırılığı Blant-Altman eğrilerinde yapılan değerlen-

\begin{tabular}{|l|c|}
\hline \multicolumn{2}{|c|}{$\begin{array}{l}\text { Tablo 1. Isı ölçümü yapılan bebeklerin klinik özellikleri ve } \\
\text { izlem yerleri }\end{array}$} \\
\hline Klinik özellikler & $\mathbf{n}=179$ \\
\hline Tartı, gr* & $2440 \pm 918$ \\
\hline Gebelik yaşı, hafta* & $35,3 \pm 3,1$ \\
\hline Cinsiyet, $n(\%)$ & \\
Kız & $71(39,5)$ \\
Erkek & $108(60,5)$ \\
\hline İzlem yeri, $n(\%)$ & \\
Küvöz & $1390(66,5)$ \\
Kot & $371(17,7)$ \\
Açık yatak & $330(15,8)$ \\
\hline
\end{tabular}

*Değerler ortalama \pm standart sapma olarak verildi

Tablo 2. Bebeklere konulan tanilar

\begin{tabular}{|l|c|c|}
\hline TANI & $\mathbf{n}$ & $\%$ \\
\hline Solunum sıkıntıları & 115 & 53,2 \\
\hline Sepsis & 41 & 12,1 \\
\hline Hiperbilirübinemi & 44 & 13,4 \\
\hline Meningomiyelosel & 24 & 1,7 \\
\hline Dehidratasyon & 21 & 0,5 \\
\hline Hipoksik iskemik ensefalopati & 24 & 2,2 \\
\hline Gebelik haftasına göre küçük bebek & 23 & 1,9 \\
\hline Mekonyum aspirasyon sendromu & 23 & 1,7 \\
\hline Diğer & 40 & 11 \\
\hline
\end{tabular}

Tablo 3. Bebeklerin Isı ölçüm sonuçları

\begin{tabular}{|l|c|c|}
\hline & $\begin{array}{c}\text { Ölçüm } \\
\text { sonucu }\end{array}$ & $\begin{array}{c}\text { Üst ve alt } \\
\text { aralık }\end{array}$ \\
\hline Civalı cam koltuk altı termometre, $\left({ }^{\circ} \mathrm{C}\right)$ & $36,7 \pm 0,34$ & $35,2-38,9$ \\
\hline Digital koltuk altı termometre, $\left({ }^{\circ} \mathrm{C}\right)$ & $36,6 \pm 0,40$ & $35,2-38,2$ \\
\hline Temassız infrared alın termometresi, $\left({ }^{\circ} \mathrm{C}\right)$ & $37,2 \pm 0,40$ & $35,8-37,2$ \\
\hline
\end{tabular}

*Değerler ortalama \pm standart sapma olarak verildi. dirmede, temassız infrared alın termometresinin civalı ve dijital termometreye göre ortalama $0,59^{\circ} \mathrm{C}$ ve $0,57^{\circ} \mathrm{C}$ daha yüksek olduğu belirlendi (Şekil 1). İnfrared alın termometresi ile civalı termometre karşılaştııımasında (Şekil 1A), infrared alın
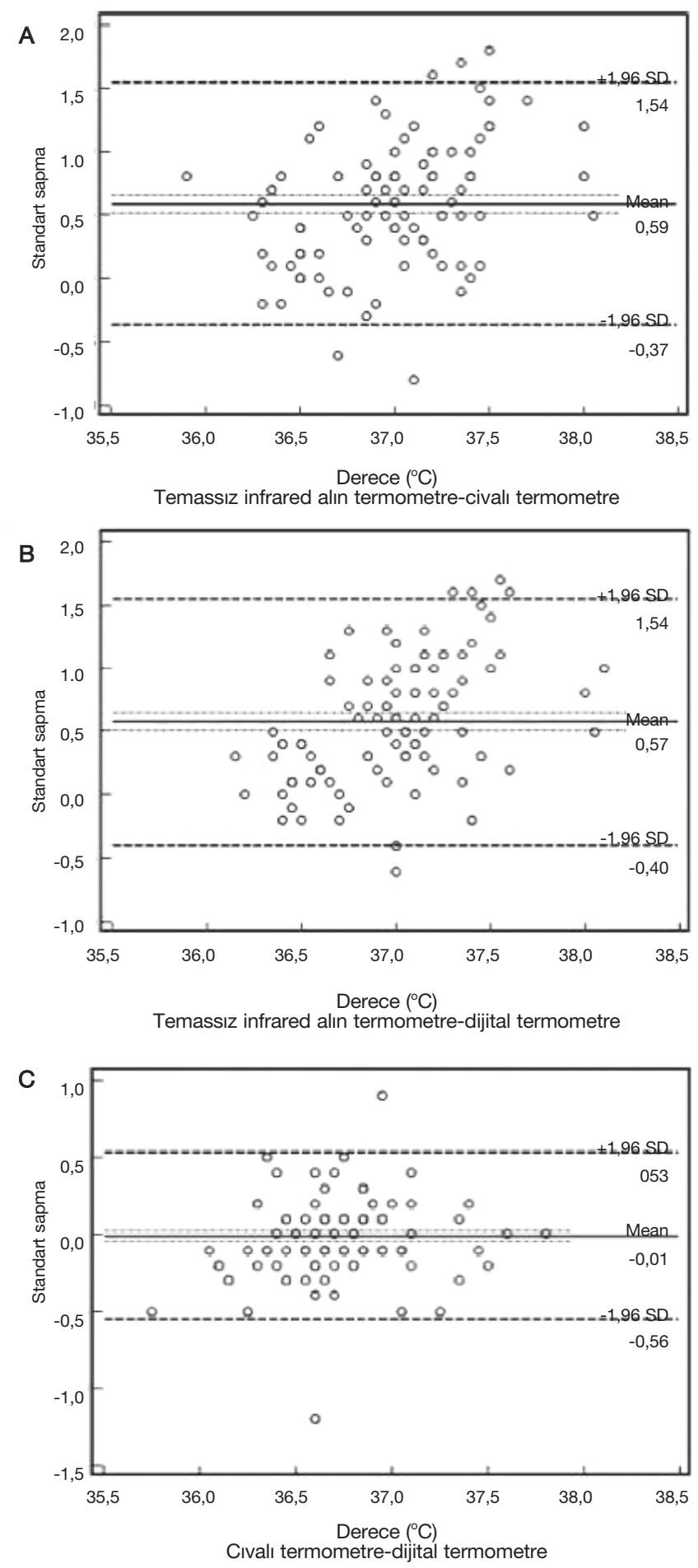

Şekil 1. Tüm ölçümlerin ortalama değerlerinin Bland-Altman eğrileri ile karşlaștırılması. Orta cizgi ortalamayı, üst ve alt çizgi $\pm 1,96$ standart sapmadaki değerleri göstermektedir 
termometresinin \%95 güvenirlikte civalı dereceden $1,54{ }^{\circ} \mathrm{C}$ yüksek ve $0,37^{\circ} \mathrm{C}$ düşük olduğu belirlendi. İnfrared alın termometresi ile dijital termometre karşılaştıılmasında (Şekil 1B), infrared alın termometresinin \%95 güvenirlikte dijital dereceden $1,54{ }^{\circ} \mathrm{C}$ yüksek ve $0,40{ }^{\circ} \mathrm{C}$ düșük olduğu belirlendi. Civalı derece ile dijital termometre karşılaştırımasında iki ölçüm arasında anlamlı fark saptanmadı (Şekil 1C).

Ölçümlerin yapıldığı yer değerlendirildiğinde; küvözde, beşikte ve açık yatakta alınan ölçümlerde temassız infrared alın termometresi sonuçlarının dijital ve civalı termometre ile alınan sonuçlara göre anlamlı olarak yüksek olduğu saptandı $(p<0,001)$. Civalı ve dijital termometre ile yapılan ölçümlerde fark saptanmadı (Tablo 4). Bebeklerin yattıkları ısı ortamının daha standart olduğu küvöz ortamındaki yapılan derece ölçümlerinde (her bir termometrede 1390 ölçüm), ortalama ölçüm değerleri infrared termometrede $37,26 \pm 1,04{ }^{\circ} \mathrm{C}$, dijital termometrede $36,73 \pm 0,39^{\circ} \mathrm{C}$ ve civalı termometrede $36,72 \pm 1,05^{\circ} \mathrm{C}$ olarak saptandı. Küvöz ortamında yapılan ölçümlerde infrared termometre sonuçlarının yüksek olduğu belirlendi (Tablo 4).

Çalışmaya alınan gebelik süresi 35 hafta ve altındaki bebekler değerlendirildiğinde temassız infrared alın termometresi ile yapılan ölçümlerin dijital termometre ve civalı termomet- reye göre yüksek olduğu, dijital termometre ve civalı termometre ile yapılan ölçümlerde ortalamalar farkı 0,029 saptanırken bu farkın istatiksel olarak anlamlı olmadığı saptandı (p:0,002) (Tablo 5). Gebelik süresi $>35$ hafta olan bebeklerde ise civalı termometre ve dijital termometre ile yapılan ölçümler arasında anlamlı fark bulunmazken, temassız infrared alın termometresi ileyapılan ölçümlerin bu iki yönteme göre yüksek olduğu görüldü (Tablo 5). Doğum ağırlığı $\leq 1250$ gr olan yenidoğan bebeklerde her üç ölçüm yöntemi arasında fark saptanırken, doğum ağırlığı >1250 gr olan bebeklerde civa ve dijital termometre ölçümleri arasında fark saptanmadı (Tablo 6). Temassız infrared alın termometresi için yapılan Roc eğirisinde $37,2^{\circ} \mathrm{C}$ kesim noktasında duyarllığı \%81, özgünlüğü \%50 olarak saptandı [\%95 güven aralı̆ı $(41,6-58,4)]$ (Şekil 2).

\section{Tartışma}

Yenidoğanda kararlı vücut ısısının devamlıı̆̆ının sağlanması, bebeğin en iyi koşullarda büyümesi ve gelişmesi için gereklidir. Bu sebeple YYBB'de temel bakım hizmetlerinin başında gelen vücut ısısının düzenli ve doğru teknikle izlemi oldukça önem kazanmaktadır. Erişkinlerde ateş ölçümlerinde kabul edilen vücut ısı ölçüm ilkelerinin, ço-

Tablo 4. İzlem yerinin ölçüm sonuçları üzerine etkisi**

\begin{tabular}{|c|c|c|c|c|c|c|}
\hline \multicolumn{7}{|c|}{ İzlem yeri } \\
\hline Ölçüm yöntemleri & Beşik & $p^{*}$ & Açık yatak & $p^{*}$ & Küvöz & $p^{*}$ \\
\hline Toplam ölçüm sayısı & 1113 & & 990 & & 4170 & \\
\hline İnfrared termometre & $37,06 \pm 0,45$ & $<0,001$ & $37,24 \pm 0,46$ & $<0,001$ & $37,26 \pm 1,04$ & $<0,001$ \\
\hline Dijital termometre & $36,50 \pm 0,39$ & & $36,68 \pm 0,38$ & & $36,73 \pm 0,39$ & \\
\hline İnfrared termometre & $37,06 \pm 0,45$ & $<0,001$ & $37,24 \pm 0,46$ & $<0,001$ & $37,26 \pm 1,04$ & $<0,001$ \\
\hline Civalı termometre & $36,57 \pm 0,39$ & & $36,70 \pm 0,37$ & & $36,72 \pm 1,05$ & \\
\hline Dijital termometre & $36,56 \pm 0,39$ & 0,568 & $36,68 \pm 0,38$ & 0,156 & $36,73 \pm 0,39$ & 0,759 \\
\hline Civalı termometre & $36,57 \pm 0,39$ & & $36,70 \pm 0,37$ & & $36,72 \pm 1,05$ & \\
\hline
\end{tabular}

* Paired samples t testi

** Değerler ortalama \pm standart sapma olarak verildi

Tablo 5. Gebelik süresinin ölçüm sonuçlarına etkisi**

\begin{tabular}{|c|c|c|c|c|}
\hline & \multicolumn{4}{|c|}{ Gebelik süresi } \\
\hline & $\leq 35$ hafta & & $>35$ hafta & \\
\hline Ölçüm sayısı & 2979 & & 3294 & \\
\hline Ölçüm yöntemleri & & $\mathbf{p}^{*}$ & & $p^{*}$ \\
\hline İnfrared termometre & $37,34 \pm 0,50$ & $<0,001$ & $37,15 \pm 1,07$ & $<0,001$ \\
\hline Dijital termometre & $36,73 \pm 0,38$ & & $36,67 \pm 0,40$ & \\
\hline İnfrared termometre & $37,34 \pm 0,50$ & $<0,001$ & $37,15 \pm 1,07$ & $<0,001$ \\
\hline Civalı termometre & $36,76 \pm 0,38$ & & $36,65 \pm 1,09$ & \\
\hline Dijital termometre & $36,73 \pm 0,38$ & 0,002 & $36,67 \pm 0,40$ & 0,495 \\
\hline Civalı termometre & $36,76 \pm 0,38$ & & $36,65 \pm 1,09$ & \\
\hline
\end{tabular}

* Paired samples $t$ testi

** Değerler ortalama \pm standart sapma olarak verildi 
cuklarda ve özellikle yenidoğan bebeklerde de geçerli olduğu; bu ilkelere göre YYBB'de kullanılacak termometre cihazının; güvenilir, girişimsel ve travmatik olmayan, uygulandığı toplumun kültürü tarafından uygun olarak kabul edilen, kullanıcı dostu ve hijyenik özelliklerinin olması gereklidir (7). Bu amaçla araştırmamızda YYBB'de kullanımı daha pratik olan infrared alından ölçüm yapan termometre ile dijital ve civalı termometrelerin ısı ölçüm sonuçlarının karşılaştıııması amaçlandı.

Vücut ısısının ölçümünde temel amaç değişen çevre koşulları karşısında sabit olan vücut iç ısısının değerlendirilmesidir (9). Vücut ısısının ölçümünde kabul edilen altın yöntem, pulmoner arter kateteri ile ısı ölçümüdür (10). Bununla birlikte kateter ile mesane içinden yapılan ısı ölçümlerinin pulmoner arter kateter ölçümleri ile benzer olduğu bildirilmiştir $(11,12)$. Ancak her iki ölçüm yöntemi de girişimsel olmaları, komplikasyon riski taşımaları (enfeksiyon, pnömotoraks, tromboemboli ve disritmi), uygulama için deneyimli çalışan gerektirmeleri ve yüksek maliyetleri nedeniyle yaygın olarak kullanılamamaktadır (10). Yenidoğan yoğun bakım biriminde vücut ısısının ölçümü için klasik olarak koltuk altı ve rektal yollardandan civalı termometre ile dijital termometre kullanılırken, infrared timpanik membran termometresi gibi çeşitli yöntemlerin de kullanılabildiği bildirilmektedir (13). Günümüzde dijital ve timpanik termometre kullanımı giderek yaygınlık kazanmaktadır. Ancak vücut ısısının ölçümü için farklı yöntemler ile yapılan karşılaştırmalı etkinlik çalışmalarında çelişkili sonuçlar bildirilmektedir $(1,14)$.

Vücut derisi termal mozaik yapısı nedeniyle ortam ısısından büyük ölçüde etkilenmektedir (15). Bu nedenle cilt ISISInın ölçümü, vücut iç ısısının tanımlamak için kullanılacak altın standart yöntem olarak kabul edilmemektedir (16). Ancak vücut ısısının alındığı, alın ve koltuk altı bölge ateşi tanımlamak için potansiyel yanlışlık riski taşımasına rağmen halen yaygın olarak vücut ısısının değerlendirilmesi amacıyla en sık kullanılan bölgeleri oluşturmaktadır. Mayfield ve ark.'ları (17) koltuk altı alanda bulunan kahverengi yağ dokusunun hücresel metabolik hız ve oksijen tüketimini arttırdığını, bu nedenle ISı üretiminin bu bölgede yükselebileceğini belirtmişlerdir. Rektal termometreyle ISI ölçümü, travmatik rektum yaralanması, fekal patojenlerin yayılma riskini arttırması, vagal uyarı yapabilmesi, hasta ve ebeveynlerin duygusal yapısını bozabilmesi gibi nedenlerle daha az sıklıkta kullanılmaktadır (9).

Illave olarak rektal yolla ısı ölçümü, immün yetersizliği veya pıhtılaşma bozukluğu olan hastalarda uygun bir yöntem olarak kabul edilmemektedir $(10,12)$. Rektal yolla vücut ısısının ölçümü ile ilgili çalışmalarda, bu yöntemin vücut iç sıcaklığını yavaş ve sınırlı olarak yansıttığı gösterilmiştir

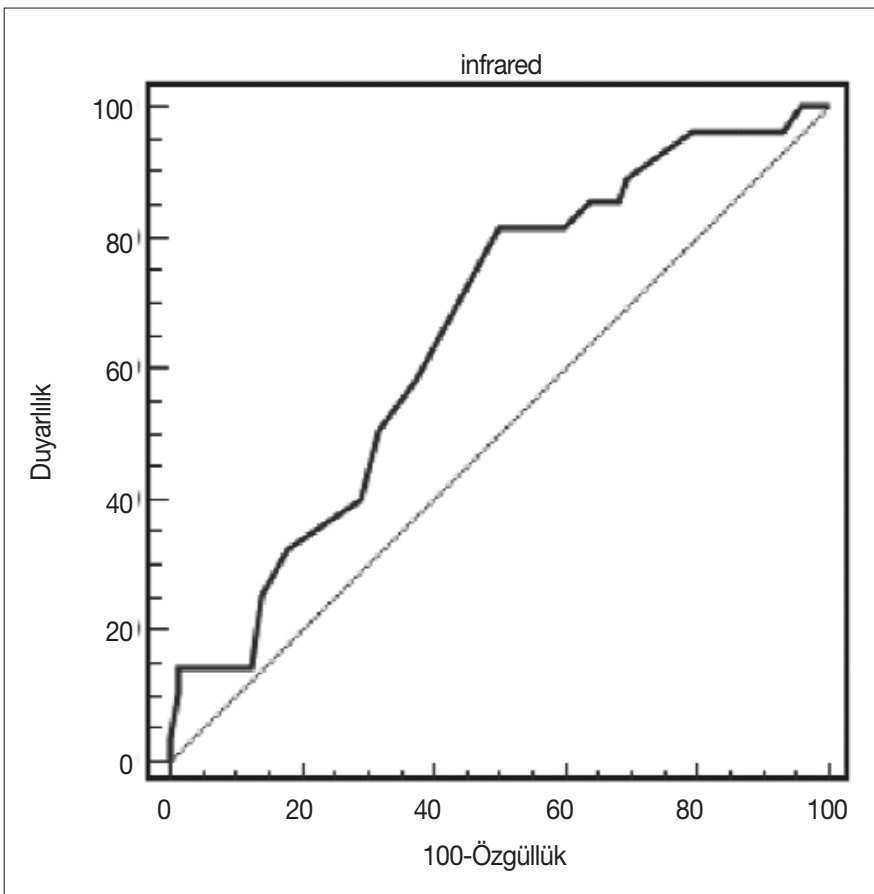

Şekil 2. Temassız infrared alın termometresi ROC eğrisi. $37,2^{\circ} \mathrm{C}$ kesim noktasında duyarlılık $\% 81$, özgünlük $\% 50$ olarak saptandı. $\% 95 \mathrm{Cl}(41,6-58,4)$

Tablo 6. Doğum ağırlığının ölçüm sonuçlarına etkisi*

\begin{tabular}{|c|c|c|c|c|}
\hline & \multicolumn{4}{|c|}{ Ölçüm esnasındaki bebeğin ağırlığı } \\
\hline & $\leq 1250 \mathrm{~g}$ & & $>1250 \mathrm{~g}$ & \\
\hline Ölçüm sayısı & 432 & & 5841 & \\
\hline Ölçüm yöntemleri & & $\mathbf{p}^{*}$ & & $p^{*}$ \\
\hline İnfrared termometre & $37,34 \pm 0,48$ & $<0,001$ & $37,21 \pm 1,08$ & $<0,001$ \\
\hline Dijital termometre & $36,70 \pm 0,44$ & & $36,68 \pm 0,40$ & \\
\hline İnfrared termometre & $37,34 \pm 0,48$ & $<0,001$ & $37,21 \pm 1,08$ & $<0,001$ \\
\hline Civalı termometre & $36,74 \pm 0,42$ & & $36,67 \pm 1,09$ & \\
\hline Dijital termometre & $36,70 \pm 0,44$ & 0,036 & $36,68 \pm 0,40$ & 0,613 \\
\hline Civalı termometre & $36,74 \pm 0,42$ & & $36,67 \pm 1,09$ & \\
\hline
\end{tabular}

* Paired samples $t$ testi

** Değerler ortalama \pm standart sapma olarak verildi 
$(10,13)$. Yukarıdaki bilgiler eşliğinde koltuk altı ve rektal yolla yapılan ölçümler yenidoğan bebeklerde tam olarak arzulanan ısı ölçüm yöntemi tanımını karşılayamamaktadır.

Infrared teknolojinin gelişmesi ile kulak zarından infrared yayılım ölçümü esasına dayanan timpanik termometreler üretilmiştir. Bu termometrelerin uygulama kolaylığı, civalı termometreye göre daha çekici olmaları, yeterli deneyime erişmeden piyasaya girmesine neden olmuştur (12). TemasSIz infrared alın termometresi ise özellikle SARS (severe acute respiratory syndrome) salgını sırasında uzakdoğuda toplumda ateş taraması için yaygın olarak kullanılmış, çocuklarda temassız infrared alın termometresinin duyarlıı̆ının yüksek olduğu, özgünlüğünün düşük olduğu, ancak tarama amacıyla kullanılabileceği bildirilmiştir (4). Güncel bilgiler değerlendirildiğinde YYBB'de temassız infrared alın termometresi kullanımı ile ilgili bir çalıșma bulunmamaktadır $(1,8)$. Erişkin hastalarda Liu ve ark.'ları (20) tarafından Tayvan'da yapılan bir çalışmada temassız infrared alın termometresiyle yapılan ölçümlerde, timpanik termometreye göre vücut ısısının daha fazla saptandığı ve daha fazla sapma olasılığı olduğu bildirilmiştir.

Temassız infrared alın termometresi ile yenidoğan bebeklerde ilk kez yapılan çalışmamızda, temassız infrared alın termometresinin koltuk altı civalı ve dijital termometreye göre vücut Isısını sırasıyla ortalama $0,59{ }^{\circ} \mathrm{C}$ ve $0,57^{\circ} \mathrm{C}$ daha fazla olarak ölçtüğü belirlendi. Temassız infrared alın termometresi ölçümleri üzerine bebeklerin izlem yerinin, gebelik haftalarının ve ağırlıklarının etkisi değerlerlendirildi. Buna göre temassız infrared alın termometresi ile bebeklerin izlemlerinin yapıldığı her üç izlem yerinde (beşik, küvöz ve açık yatak) dijital ve civalı termometreye göre yüksek sonuçlar saptandı. Bu durumda bebeklerin izlendikleri ortamın ölçüm sonuçları üzerine etkisinin olmadığı, dijital ve civalı termometre arasında fark saptanmamasının bu sonucu doğruladığı kanısına varıldı.

Gebelik haftası ve ölçüm esnasındaki ağırlık değerlendirildiğinde, gebelik yaşı $\leq 35$ hafta olan bebekler ile $>35$ hafta olan bebeklerin sonuçları arasında temassız infrared alın termometresi ölçümlerinde fark saptanmadı. Buna göre gebelik haftasının temassız infrared termometre ölçümü üzerine etkili olmadığı düşünüldü. Ölçüm esnasındaki bebeklerin güncel tartılarına göre değerlendirme yapıldığında hem $\leq 1250 \mathrm{gr}$ bebeklerde hem de $>1250 \mathrm{gr}$ olan bebeklerde temassız infrared alın termometresi ölçümlerinin yüksek sonuçlar verdiği, dijital ve civalı ölçümler arasında fark olmadığı saptandı. Buna göre tartının temassız infrared termometre ölçümleri üzerine anlamlı fark yaratmadığı sonucuna varıldı.

Günümüzde çocuklarda yapılan çalısmalara göre temassız infrared alın termometresi, temaslı alın termometre ölçümlerine benzer özgünlük ve duyarllığa sahiptir (4). Ancak Hong Kong'da çocuk yaş grubunda yapılan çalışmada temassız infrared alın termometresi ile infrared timpanik membran termometresi karşılaştrılmış, temassız infrared alın termometresinin güven aralığının geniş olduğu, yalnızca geniş ölçekli toplum taramalarında ateşin tayini için kullanılabileceği, klinik izlemde kullanılamayacağı ve yanlış pozitiflik oranının yüksek saptandığı bildirilmiştir (4). Çalışmalarda temassız infrared alın termometresinin duyarlıığının \%17-90 ve özgünlüguünün \%73-98 aralığında olduğu bildirilmektedir $(4,20)$. Bizim çalışmamızda da benzer şekilde temassız infrared alın termometresinin duyarlıı̆ı ve özgünlüğü düşük saptandı.

Çalışmamızda YYBB'de temassız infrared alın termometresi ölçümlerinin, civalı ve dijital termometreye göre yüksek sonuçlar verdiği; ölçümlerin bebeklerin gebelik haftala$\mathrm{rl}$, tartıları ve izlem yerlerinden etkilenmediği belirlendi. Bu nedenle temassız infrared alın termometresinin, YYBB'deki bebeklerde günlük izlemde vücut ısısının değerlendirilmesinde kullanılmasının uygun olmadığı sonucuna varıldı.

\section{Kaynaklar}

1. Asher C, Northington L. Position statement for measurement of temperature/fever in children. J Pediatr Nurs 2008; 23: 234-6. Abstract / PDF

2. Blumenthal I. Should we ban the mercury thermometer? Discussion paper. J R Soc Med 1992; 85: 553-5. Abstract / Ful Text) / PDA

3. Rosenthal H M, Leslie A. Measuring temperature of NICU patients-A comparison of three devices. J Neonatal Nurs 2006; 12: 125-9. Abstract / Full Tex / PDF

4. $\mathrm{Ng}$ DK, Chan $\mathrm{CH}$, Lee RS, Leung LC. Non-contact infrared thermometry temperature measurement for screening fever in children. Ann Trop Paediatr 2005; 25: 267-75. (Abstract

5. Kambarami $R$, Chidede $O$, Pereira N. ThermoSpot in the detection of neonatal hypothermia. Ann Trop Paediatr 2002; 22: 219-23. Aabstract

6. Sehgal A, Dubey NK, Jyothi MC, Jain S. Comparison of tympanic and rectal temperature in febrile patients. Indian $\mathrm{J}$ Pediatr 2002; 69: 305-8. Abstrad)

7. Hebbar K, Fortenberry J D, Rogers K, Merritt R, Easley K. Comparison of temporal artery thermometer to standard temperature measurements in pediatric intensive care unit patients. Pediatr Crit Care Med 2005; 5: 557-61. Abstract

8. Klaus $\mathrm{MH}$, Fanaroff $\mathrm{AA}$. The physical environment. In: Klaus $\mathrm{MH}$, Fanaroff AA (eds). Care of the high risk neonate. 5th ed. Edinburgh: Sauders, 2001: 130-46.

9. Devrim I, Kara A, Ceyhan M, et al. Measurement accuracy of fever by tympanic and axillary thermometry. Pediatr Emerg Care 2007; 23: 16-9. Abstract

10. Nimah MM, Bshesh K, Callahan JD, Jacobs BR Infrared tympanic thermometry in comparison with other temperature measurement techniques in febrile children. Pediatr Crit Care Med 2006; 7: 48-55. Abstract

11. Fallis WM. Monitoring urinary bladder temperature in the intensive care unit: state of the science. Am J Crit Care 2002; 11: 38-45. Abstract/ Full Tex/ PDF

12. Lefrant JY, Muller L, de La Coussaye JE, et al. Temperature measurement in intensive care patients: comparison of urinary bladder, oesophageal, rectal, axillary, and inguinal methods versus pulmonary artery core method. Intensive Care Med 2003; 29: 414-8. Abstract / PDH

13. Cultu O, Yildirim I, Ceyhan $\mathrm{M}$, et al. Comparing body temperature measurements by mothers and physicians using mercury-in-glass, digital mercury and infrared tympanic membrane thermometers in healthy newborn babies. Turk $\mathrm{J}$ Pediatr 2008; 50: 354-8. Abstrac / Eull Tex / PDA 
14. El-Radhi AS, Patel S. An evaluation of tympanic thermometry in a paediatric emergency department. Emerg Med J 2006; 23: 40-1. Abstract) / Full Text/ PDH

15. Osinusi K, Njinyam MN. Comparison of body temperatures taken at different sites and the reliability of axillary temperature in screening for fever. Afr J Med Med Sci 1997; 26: 163-6. Abstract

16. Moya Villaescusa MJ, Sánchez Pérez A, Bermejo Fenoll A. Reliability of an infrared auditory thermometer in the measurement of oral temperature. Med Oral Patol Oral Cir Bucal 2008; 13: E385-9. Abstract

17. Mayfield SR, Bhatia J, Nakamura KT, Rios GR, Bell EF. Temperature measurement in term and preterm neonates. J Pediatr 1984; 104: 271-5. Abstrac//PDA
18. Maloney SK, Fuller A, Mitchell G, Mitchell D. Rectal temperature measurement results in artifactual evidence of selective brain cooling. Am J Physiol Regul Integr Comp Physiol 2001; 281: R108-14. Abstract / Full Tex / PDH

19. van Staaij BK, Rovers MM, Schilder AG, Hoes AW. Accuracy and feasibility of daily infrared tympanic membrane temperature measurements in the identification of fever in children. Int J Pediatr Otorhinolaryngol 2003; 67: 1091-7. Abstrac / Eull Tex / PDA

20. Liu CC, Chang RE, Chang WC. Limitations of forehead infrared body temperature detection for fever screening for severe acute respiratory syndrome. Infect Control Hosp Epidemiol 2004; 25: 1109-11. Abstract/PDA 